\title{
REPRESENTATIONS OF NATURE IN ECOTOURISM ADVERTISEMENTS
}

\author{
Dita Trčková
}

\begin{abstract}
Employing the appraisal theory and the system of transitivity, the study explores representations of nature and the human-nature relationship in ecotourism advertisements on the website Responsible Travel. It is revealed that a number of empowering discursive devices with regard to nature are employed in the data, including the allocation of the agentive role in constructive processes to inanimate natural elements, the adoption of the activation of tokens and the activation of experiences, and celebratory portrayals of nature as an aesthetically pleasing artwork and a spectacle of supernatural qualities. Yet, it is argued that the celebration and the empowerment of nature in the ecotourism advertisements tend to take place at the expense of the reproduction of the human-nature dichotomy, portraying nature as the Other.
\end{abstract}

\section{Keywords}

ecotourism advertisements, human-nature relationship, appraisal theory, transitivity analysis, ecolinguistics

\section{Introduction}

The rise of mass tourism in the second half of the 20th century with its negative effect on the environment and the increase in the environmental movement at that time initiated the establishment of an alternative strand of tourism, namely ecotourism (Dowling \& Fennell 2003). The term 'ecotourism' was coined in the early 1980 s by Ceballos-Lascuráin, who defined it as "traveling to relatively undisturbed or uncontaminated natural areas with the specific objective of studying, admiring, and enjoying the scenery and its wild plants and animals, as well as any existing cultural manifestations (both past and present) found in these areas" (quoted in Boo 1990: xiv). Since then numerous definitions of ecotourism have come into existence (cf. Fennell 2003), resulting in the concept being criticized for having become close to meaningless (Carrier \& Macleod 2005) and being often used merely for marketing purposes (Acott et al. 1998).

Nevertheless, the main criteria for ecotourism common to a number of definitions can be designated: execution of the tourism activity in a comparatively undisturbed natural environment; minimization of the negative impact of tourism; contribution to conservation of the natural environment; active involvement of 
local communities; contribution to sustainable development; and inclusion of education, appreciation and interpretation components (Buckley 2003, CeballosLascuráin 2003). These criteria can be reduced to three key characteristics of ecotourism, namely, an educative component, a sustainability component and the ethical nature of the tourist experience (Fennell 2003).

Despite its environmentally friendly aims, ecotourism has been criticized for giving privilege to the economic aspect over the environmentalist one (Buckley 2001), aiming to preserve the natural resources mainly to benefit the tourism industry itself (Dorsey et al. 2004). Yet, Russell (2007: 226) warns against an all-encompassing criticism of ecotourism and accentuates the need to distinguish between practice and good practice, claiming "the real and potential value of some forms of ecotourism".

The present study is concerned with a discourse analysis of ecotourism advertisements published on the website Responsible Travel, aiming to uncover prevailing representations of nature and the human-nature relationship. There has been a relative lack of research studies focusing on a textual analysis of ecotourism advertisements, with the exception of Dorsey et al.'s study (2004) of seven websites advertising ecotourism. Adopting an in-depth qualitative textual analysis, the authors conclude that the studied advertisements are not always consistent with the discourse of eco-sustainability, failing to discuss core principles of ecotourism, and tend to depict the landscapes as unchangeable and isolated, resulting in their commodification. A similar conclusion with regard to the portrayal of nature is reached in Stamou et al.'s (2009) critical discourse analysis concerned not with ecotourism advertisements per se but the textual material disseminated in the information centre of an ecotourism destination. The study reveals that the textual material mostly suppresses human agency and equates nature with wilderness, portraying landscapes as outside the flow of history and the social realm. Analysing a similar type of texts, Stamou and Paraskevopoulos's (2004) critical discourse study of visitor books disseminated in the information centre and at the observation site of an ecotourism destination shows that the analysed texts fail to express the duality of ecotourism, dividing rather than reconciling environmentalist and tourism images.

\section{Research objectives, data and method}

The main objective of the present study is to reveal dominant portrayals of nature and the human-nature relationship in the selected ecotourism advertisements. The first goal is to investigate evaluations and assessments of nature employed in the advertisements and the ideology of the human-nature relationship embedded in the evaluative meanings. As the studied discourse 
functions to promote natural destinations, it is to be expected that positive evaluations of nature abound in the text. The research aspires to reveal the features and values of nature which are foregrounded in order to 'sell' the destination. The second goal of the present study is to conduct a transitivity analysis of the clauses in which one of the participants is a natural phenomenon in order to examine whether nature is endowed with power and activity or is portrayed as passive, and whether mankind and nature are depicted as interconnected. Employing mainly a qualitative approach, the interest of the study lies in finding out whether ecotourism advertisements offer an alternative view of the human-nature relationship that resists the dualism of the Western Enlightenment ideology conceptualising human beings as dominating nature.

The corpus of data used in the study comprises 150 ecotourism advertisements from the category 'tours' on the website Responsible Travel. This company was chosen since it provides tours to places all over the world and since it is included among the top ten environmentally friendly travel companies in The Ecologist (2011). The collected advertisements evenly cover destinations in Kenya, Botswana, Madagascar, Bolivia, Ecuador, Europe, Australia, New Zealand, the United States and Canada. Concerning the structure of the advertisements, there is a short general description of the tour at the beginning (entitled 'Description from the holiday company'), followed by a 'Day-by-day itinerary' section, information about the holiday company (labelled 'The story of this holiday company') and a section specifying why the tour belongs to the category of responsible tourism (named 'Responsible tourism').

To analyse the human-nature relationship as constructed in the discourse of the ecotourism advertisements, the study employs critical discourse analysis (CDA) (Fairclough 1992, Weiss \& Wodak 2003, Wodak \& Meyer 2009) as its methodological framework. The major interest of CDA lies in investigating implicit and explicit power relations as manifested in language (Wodak 2009), which is viewed as having the potential to not only reproduce existing power distributions in the society but also challenge and alter them (Wodak \& Meyer 2009). One of the main initiatives of the recent strand of critical discourse studies is a shift towards the analysis of resistance discourses (Krzyżanowski $\&$ Forchtner 2016). Drawing on this initiative, the present study investigates whether ecotourism advertisements resist the human-nature dualism, deeprooted in Western thinking (Hawkes 2003), and promote a more holistic view emphasizing the interrelatedness between nature and mankind, advocated by ecolinguists (Harré et al. 1999). Given the above, this paper follows the stream of research in the recently thriving field of critical ecolinguistics (Fill \& Mühlhäusler 2001). 
The first part of the analysis, examining the language of evaluation of nature, adopts Martin and White's (2005) appraisal theory. Appraisal is subsumed under the interpersonal function of language, as it is concerned with the construction of "shared feelings and values" (Martin \& White 2005: 1). Due to the interest of this study in evaluative meanings themselves, the analysis focuses on one of the three domains of Appraisal, i.e. Attitude. This category is divided into: Affect, which accounts for expressions of feelings; Judgement, which concerns assessments of behaviour; and Appreciation, which comprises evaluations of things and natural phenomena (Martin \& White 2005). The category most relevant to the present study is Appreciation, which is further divided into three subcategories: Reaction, Composition and Valuation. Reaction is related to how a given phenomenon affects people, providing answers to the questions 'do I like it?' (i.e. what quality the phenomenon has) and 'does it catch my attention?' (i.e. what impact the phenomenon has). Composition concerns the balance and complexity of the phenomenon. The third subcategory, Valuation, accounts for the social value of the phenomenon, providing an answer to the question 'is the phenomenon worthwhile?'

During the first stage of the analysis, the author searched manually for all evaluative lexis employed with regard to nature, paying attention to both explicit expression of evaluation through attitudinal lexis and implicit evaluation through selected ideational meanings (Martin \& White 2005). All the evaluative meanings were then sorted into the three categories of Appreciation (Reaction, Composition and Valuation) and further subdivided into semantic domains.

The second part of the analysis draws on Halliday's (1985) system of transitivity, belonging to the ideational function of language due to its concern with representation of experience. Transitivity refers to the depiction of components of processes, i.e. participants, the process itself, and the circumstances, as expressed through the grammatical structure of clauses. The adopted transitivity configuration construes relations between participants as being of a particular type and assigns participants to particular power positions (cf. Goatly 2000). The present study conducts a transitivity analysis of the clauses in which one of the participants is represented by a natural phenomenon. Recurrent transitive configurations are searched for, with the focus placed on the semantic roles that nature tends to play and the types of processes employed.

\section{Analysis}

\subsection{System of Appreciation}

The analysis reveals that although evaluative lexis abounds in the studied discourse, the same, relatively small set of attitudinal meanings with regard to 
nature is used repeatedly across the advertisements, with most of the evaluations being grammatically realized by adjectives and a few by noun phrases.

\subsubsection{Reaction category}

The evaluations of nature belonging to the category of Reaction, which is related to affection, fall into four main, overlapping semantic domains: the portrayals of nature as an aesthetically pleasing artwork, as a spectacle, as magic, and as a paradise. The most common lexical materializations of the four domains, with the number of their occurrences in the corpus, are included in Table 1.

The depiction of nature as aesthetically pleasing is explicitly conveyed through the repeated use of the noun 'beauty' (wilderness of haunting beauty) and a range of adjectives, including 'beautiful' (devastatingly beautiful dunes), 'stunning' (stunning scenery), 'gorgeous' (gorgeous archipelago), 'picturesque' (picturesque landscapes), 'scenic' (scenic area), 'fanciful' (fanciful shapes), 'lovely' (lovely coastline) and 'delightful' (delightful waterfalls). Such a representation is expressed in the advertisements not only explicitly through attitudinal lexis but also implicitly through the selected ideational meanings. Nature is implicitly depicted as an artwork appealing to one's eyes by the recurrent emphasis placed on colours (blue-green vistas, the landscape takes on remarkable oranges and reds, turquoise waters, pink-frosted shores and purple hills), often used in combination with a gemstone to highlight the preciousness of the visual effect, as in sapphire-blue waters and emerald green hills. The visual impression is further highlighted by the ascription of a shining character to nature, as in a glaring plain, sparkling shores and gleaming lakes.

The second group of attitudinal lexis belonging to the Reaction category of Appreciation foregrounds the great impression that nature makes, portraying it as a spectacle. Such an image is directly established by the adoption of the expressions 'spectacular' (spectacular sunset), 'spectacle' (a spectacle of wildlife), 'dramatic' (dramatic cliffs) and 'sensational' (sensational wildlife). It is also conveyed by adjectives denoting grand impressiveness, namely 'magnificent' (magnificent creatures), 'mighty' (mighty Blue Nile), 'majestic' (majestic backdrops), 'epic' (epic landscape) and 'imposing' (imposing trees) as well as hyperbolic adjectives emphasizing the effect of nature on people, including 'stunning' (stunning scenery), 'breathtaking' (breathtaking coastline), 'awe-inspiring' (awe-inspiring views), 'jaw-dropping' (jaw-dropping mountain scenery), 'staggering' (staggering sight) and 'dazzling' (dazzling landscapes). Although not explicitly attitudinal, frequently employed hyperbolic adjectives denoting the big size of natural phenomena, such as 'large', 'massive', 'vast', 'huge', 'colossal' and 'endless', also contribute to the depiction of nature as a spectacle. 
The portrayals of nature as aesthetically pleasing and spectacular reflect and reproduce the ideology of Romanticism, which placed emphasis on personal experience of beauty and sublimity of nature and saw the merit of nature in providing fulfilling perceptual experience (Urry 2002). On the one hand, the representation of nature as a spectacle evokes respect and admiration, and endows nature with power. On the other hand, it provides nature with a static character, making it resemble a monument to be gazed at and admired, separated from people. The human-nature dichotomy in such a portrayal is therefore sharpened.

The boundary between human beings and nature is further intensified by the adoption of the conceptual metaphor of 'nature is magic', materialized in the repeated use of the expressions 'magical' (magical savannah plains), 'enchanting' (enchanting creatures), 'charming' (charming lake) and 'mesmerizing' (mesmerizing skies). Supernatural qualities are also conveyed by the adjectives 'out of this world' (out of this world scenery), 'otherworldly' (otherworldly landscape), 'ethereal' (ethereal vistas) and 'unearthly' (unearthly Death Valley).

The fourth domain of the Reaction category entails the portrayal of nature as a paradise. The advertisements idealize natural phenomena by using evaluative lexis such as 'paradise' (wildlife paradise), 'idyllic' (idyllic beach setting) and 'paradisiac' (paradisiac beaches). Such a depiction reproduces the romantic concept of a rural idyll, which views nature as a provider of peacefulness, relaxation and an escape from a stressful city life (Stamou \& Paraskevopoulos 2004). The employment of fairy-tale-like motifs of magic and paradise serves well the marketing purpose of the advertisements; yet, it distances nature from human beings, portraying it metaphorically as being part of a different world.

\begin{tabular}{|l|l|}
\hline Semantic domains & $\begin{array}{l}\text { Lexical materializations with the number of } \\
\text { their occurrences in the data }\end{array}$ \\
\hline nature as an aesthetically-pleasing artwork & beautiful (146) \\
& stunning (126) \\
beauty (47) \\
reference to colours (45) \\
scenic (44) \\
picturesque (15) \\
sparkling (14) \\
lovely (10) \\
reference to gems (8) \\
gorgeous (4) \\
delightful (4) \\
fanciful (1) \\
glaring (1) \\
gleaming (1)
\end{tabular}




\begin{tabular}{|c|c|}
\hline Semantic domains & $\begin{array}{l}\text { Lexical materializations with the number of } \\
\text { their occurrences in the data }\end{array}$ \\
\hline nature as a spectacle & $\begin{array}{l}\text { large (173) } \\
\text { stunning (126) } \\
\text { spectacular (121) } \\
\text { magnificent (43) } \\
\text { mighty (36) } \\
\text { vast (32) } \\
\text { huge (29) } \\
\text { dramatic (24) } \\
\text { breathtaking (20) } \\
\text { massive (19) } \\
\text { awe-inspiring (18) } \\
\text { majestic (17) } \\
\text { epic (17) } \\
\text { endless (13) } \\
\text { spectacle (10) } \\
\text { sensational (7) } \\
\text { imposing (4) } \\
\text { jaw-dropping (4) } \\
\text { staggering (3) } \\
\text { dazzling (2) } \\
\text { colossal (1) }\end{array}$ \\
\hline nature as magic & $\begin{array}{l}\text { magical (7) } \\
\text { enchanting (5) } \\
\text { out of this world (5) } \\
\text { charming (4) } \\
\text { mesmerising (3) } \\
\text { otherworldly (2) } \\
\text { unearthly (1) } \\
\text { ethereal (1) }\end{array}$ \\
\hline nature as paradise & $\begin{array}{l}\text { paradise (25) } \\
\text { idyllic (7) } \\
\text { paradisiac (1) }\end{array}$ \\
\hline
\end{tabular}

Table 1: Reaction category semantic domains and their lexical materializations with the number of their occurrences in the corpus

\subsubsection{Composition category}

The attitudinal lexis belonging to the perception-related category of Composition, which refers to the balance and complexity of natural phenomena, can be divided into three main semantic domains: nature as diverse, nature as prolific, and nature as pure. The lexical materializations of these domains and the frequency of their occurrence can be found in Table 2 . 
The advertisements repeatedly stress that the natural areas to be visited are characteristic of their variety of wildlife, materialized in the recurrent use of: 'variety' (incredible variety of birds), 'different' (many different species), 'diverse' (diverse wildlife), 'array' (astonishing array of habitats), 'myriad' (a myriad of big game) and 'mixture' (astonishing mixture of game). The focus is also placed on the large number of natural phenomena to be found in the visited areas, as reflected in the adoption of the words 'abundance' (an abundance of game species), 'numerous' (numerous antelopes), 'plentiful' (plentiful wildlife), 'prolific' (prolific bird life), 'bountiful' (bountiful wildlife) and 'profusion' (profusion of wildlife). The combination of the notions of diversity and abundance results in the metaphorical construction of nature as rich (e.g. wildlife-rich and wealth of zebra). The third group of evaluative lexis in the Composition category depicts nature as pure, unpolluted and untouched: 'pristine' (pristine wilderness area), 'clear' (clear waters), 'pure' (pure waters) and 'clean' (clean water).

The choice of these three particular domains of evaluative meanings, rather than for instance 'balanced' or 'harmonious', to promote natural areas in the advertisements suggests that the image of nature to be appreciated is one that is prosperous, reflecting one of the Western values, and devoid of human activity, which in effect widens the human-nature dualism.

\begin{tabular}{|l|l|}
\hline Semantic domains & $\begin{array}{l}\text { Lexical materializations with the number of } \\
\text { their occurrences in the data }\end{array}$ \\
\hline nature as diverse & $\begin{array}{l}\text { variety (60) } \\
\text { rich (54) } \\
\text { different (30) } \\
\text { diverse (26) } \\
\text { array (25) } \\
\text { myriad (5) } \\
\text { mixture (5) }\end{array}$ \\
\hline nature as prolific & $\begin{array}{l}\text { rich (54) } \\
\text { abundance (16) } \\
\text { numerous (16) } \\
\text { plentiful (14) } \\
\text { prolific (2) } \\
\text { bountiful (2) } \\
\text { profusion (1) }\end{array}$ \\
& pristine (29) \\
clear (21) \\
pure (5) \\
clean (3)
\end{tabular}

Table 2: Composition category semantic domains and their lexical materializations with the number of their occurrences in the corpus 


\subsubsection{Valuation category}

The variety of semantic domains to which evaluative lexis from the cognitionrelated category of Valuation belong is the highest of the three categories of Appreciation; the main values ascribed to the advertised natural phenomena include: uniqueness, fame, remoteness and an unspoiled character, proximity to ecotourists, and fertility and healthiness. Their lexical materializations and the number of occurrences are shown in Table 3.

The prevailing Valuation lexis in the data is that emphasizing the uniqueness of the promoted wildlife areas, manifested in the use of the expressions 'unique' (utterly unique biosphere), 'unparalleled' (unparalleled ornithological opportunities), 'unrivalled' (unrivalled in its remoteness and space) and 'found nowhere else on earth' (countless species found nowhere else on earth). The sense of uniqueness is also conveyed by the repeated use of adjectives in the superlative form, as in one of the last remaining sanctuaries, one of earth's most phenomenal geological features, one of the world's last wilderness and one of the best areas for wildlife. The precious and valuable character is further established in the metaphorical portrayals of the advertised natural phenomena as a hidden gem and hidden treasure. The employment of the value of uniqueness targets the tourist's quest for the extraordinary, as pointed out by Thurlow \& Jaworski (2010). Its marketing purpose and commodifying effect is shared by another value ascribed to the ecotourist destinations, that is the value of fame (e.g. explore most renowned wildlife hot spots). Less commodifying characteristics, such as 'profound' and 'educational', are absent in the data.

Two other values recurrently ascribed to the ecotourist areas are remoteness and an unspoiled character. The advertisements highlight the fact that the areas to be visited are far away from civilization, as in remote wilds, off the beaten track places, well away from the usual tourist trail and truly wild wilderness. Nature to be appreciated is thus equated with wilderness and it is devoid of people. Such a portrayal is intensified by the depiction of the areas as unspoiled by human activities (one of the last remaining unspoiled wilderness areas and untouched wilderness), contributing to the construction of the human-nature dualism, as already discussed under the Composition category (evaluative lexis of 'purity' in Section 3.1.2). This stands in contrast to the values of intimacy and proximity, adopted to promote the ecotourism experience, as when, for instance, the advertisements promise intimate bush experience and meeting of a wild Mountain Gorilla face-to-face. Thus, while visitors are expected to interconnect with natural phenomena, mankind in general is separated from nature in the advertisements. 
The last two values repeatedly allocated to the advertised natural destinations are fertility and healthiness. Visitors are allured, for instance, by visiting fertile plains and encountering a healthy population of White and Black rhinos. The association of nature with health, one of the most important values of Western society, has a celebratory, empowering effect.

\begin{tabular}{|l|l|}
\hline Semantic domains & $\begin{array}{l}\text { Lexical materializations with the number of } \\
\text { their occurrences in the data }\end{array}$ \\
\hline uniqueness & $\begin{array}{l}\text { unique (76) } \\
\text { gem (12) } \\
\text { unparalleled (9) } \\
\text { unrivalled (5) } \\
\text { treasure (4) } \\
\text { found nowhere else on earth (3) }\end{array}$ \\
\hline fame & $\begin{array}{l}\text { famous (119) } \\
\text { renowned (15) }\end{array}$ \\
\hline remoteness and an unspoiled character & $\begin{array}{l}\text { remote (89) } \\
\text { off the beaten track (39) } \\
\text { untouched (7) } \\
\text { unspoiled (6) } \\
\text { truly wild (1) }\end{array}$ \\
\hline proximity to tourists & $\begin{array}{l}\text { intimate (7) } \\
\text { face-to-face (1) }\end{array}$ \\
\hline fertility and healthiness & $\begin{array}{l}\text { fertile (12) } \\
\text { healthy (5) }\end{array}$ \\
\hline
\end{tabular}

Table 3: Valuation category semantic domains and their lexical materializations with the number of their occurrences in the corpus

\subsection{Transitivity analysis}

Based on a close reading of the advertisements and a search for discursive tendencies, three recurrent transitivity patterns featuring a natural phenomenon as a participant have been revealed. In each of them, nature occupies a different semantic role, listed according to their empowering effect: the Actor, the Experience and the Goal. The following sections describe each of the three transitivity patterns in more detail, classifying the employed verbal processes into semantic domains and discussing the underlying portrayal of the humannature relationship. 


\subsubsection{Nature as the Actor}

The most empowering semantic role allocated to natural elements in the advertisements is the Actor of material processes. This role depicts nature as active and agentive, combating the image of nature as passive and powerless. Importantly, it is ascribed not only to animate natural phenomena (example (1)), but also inanimate natural objects (examples (2), (3) and (4)).

Material processes the Actors of which are animals include, for instance, 'come to lick', 'come for breeding', 'prance', 'look after', 'play around', 'bathe', 'circle', 'graze', 'spar' and 'munch away'. If a transitive verb is employed, the role of the Goal is allocated either to another animal or an inanimate natural phenomenon. Human beings are thus excluded as participants from such clauses, figuring merely as observers.

(1) tens of thousands of hoofed animals roam in a constant and unremitting search for the fresh grasslands

Material processes the Actors of which are inanimate natural objects tend to fall into three semantic domains: verbs of provision, including 'provide', 'offer', 'give', 'deliver' and 'yield' (example (2)); verbs of creation, such as 'create', 'form', 'carve' and 'sculpt' (example (3)); and verbs of growth, namely 'grow', 'flourish' and 'thrive' (example (4)). Such clauses empower nature by depicting it as the doer of constructive processes, a role rarely ascribed to inanimate natural elements in English discourse according to Halliday (2001), who asserts that inanimate objects tend to be portrayed as acted upon and when in the role of the Actor, they often figure as the doer of destructive processes in catastrophic contexts.

(2) imposing camel thorn trees provide shade for huge black-mane lions

(3) giant sandstone boulders have been sculpted by wind and rain

$$
\text { 'spiny forest' of cacti and other plants that thrive in arid environments }
$$

Other nature activating grammatical devices employed in the advertisements include the activation of tokens and the activation of experiences (Goatly 2000: 285). The activation of tokens comprises a transformation of relational processes, portraying nature as static, into material ones. For instance, instead of there is a vast 300 square kilometre crater in front of you, the advertisements opt for a vast 300 square kilometre crater stretches out in front of you, and instead of 
there is Mount Rainier in the Pacific Northwest, the advertisements assert that Mount Rainier looms large in the Pacific Northwest. Other material processes employed in the activation of tokens include 'line', 'fringe', 'ring', 'run through', 'cut its way through', 'sit', 'stretch', 'stand' and 'dominate'. The second type of activation, the activation of experiences, involves the transformation of Experiences in mental processes into Actors in material processes, such as the reconstruction of you will love the scenery into the scenery will blow your mind. Other verbs adopted in the activation of experiences in the data include 'leave you in awe', 'make you return', 'appeal to you', 'attract you', 'blow you away', and 'compete for your attention'.

\subsubsection{Nature as the Experience}

Another semantic role played by natural phenomena in the studied advertisements is the Experience of mental processes, with the role of the Experiencer allocated to human beings. Such a transitivity pattern places nature into a more static and a less active position than the activation of experiences discussed above.

Mental processes used in the clauses encompass three types (cf. Table 4): processes of affection (if you love wildlife), processes of experience (experience the beautiful landscapes of Central Australia) and processes of sensing (look at giant cacti and the birds). As can be seen in Table 4, the most frequent processes of sensing are those involving eyesight. Advertisers thus promote the primacy of the visual over other senses in the tourist's experience of nature, which corresponds to Urry's (2002) emphasis on the importance of the tourist gaze in people's encounter with natural phenomena. The only other processes of sensing occurring in the data are those experienced through ears, namely 'hear' (hear hippos wallowing) and 'listen to' (listen to the sounds of wild), while those of touching and smelling, which would provide for a more complex experience of nature, are absent in the data.

\begin{tabular}{|l|l|}
\hline Types of mental processes & Tokens \\
\hline processes of affection & love, admire, appreciate, marvel at, wonder at \\
\hline processes of experience & experience, soak up, embrace, enjoy \\
\hline processes of sensing & $\begin{array}{l}\text { look at, gaze at, spot, watch, catch sight of, glimpse, view, keep } \\
\text { your eyes peeled for, lay eyes upon, hear, listen to }\end{array}$ \\
\hline
\end{tabular}

Table 4: Types of mental processes with examples 
On the whole, by being allocated the role of the Experience, natural phenomena are endowed with power to impact on people's minds, feelings and experiences. Yet, the transitivity pattern discussed above reproduces an anthropocentric, rather than a biocentric attitude to nature.

\subsubsection{Nature as the Goal}

The third semantic role recurrently occupied by nature in the advertisements is the role of the Goal of material processes the Actor of which is a human being. Such a transitivity pattern ascribes to nature the most passive and powerless position of the three transitivity configurations. Yet, the verbal processes employed in these clauses have a partial empowering effect for nature as they draw on environmental discourse, highlighting educative, interactive and conservation elements.

More specifically, the material processes in these clauses fall into four main semantic domains: processes of learning, processes of exploration, processes of interaction and processes of protection. The educational component, a key feature of ecotourism (cf. Section 1), defines the first group of material processes, represented by the verbs 'learn' (learn about different animal species), 'teach' (the tour leaders always teach the clients to allow the wildlife to have right of way) and 'educate' (educate all our travelers on the importance of protecting the Galapagos). Concerning the role of the educator, it tends to be left unspecified when the verb 'learn' is used, implying that it is the tourist experience itself educating the ecotourist, while it is ascribed either to the travel company (we teach guests about responsible tourism) or local people (the villages and communities can educate on how to preserve the way of life in their area) when the verbs 'teach' and 'educate' are employed. Thus, although nature is the object of the learning process, it is excluded from the role of the one that educates. The educational element is also partly subsumed in the processes of exploration, as evidenced, for instance, by the verbs 'explore' (explore the wonders of the Masai Mara eco-system), 'find' (find the elephants, herds of antelope and lions around the waterholes), 'look for' (look for myriad orchid species), 'search for' (search for the famous Joshua Tree), 'discover' (discover the incredible Galapagos Islands) and 'go in search of' (go in search of meerkats), which, in contrast to sensory processes, demand of people effort and an active approach to nature.

The interactive aspect embedded in the third group of material processes, such as 'interact with' (you will interact with wild animals), 'get in touch with' (you can really get in touch with the bears in their natural habitat), 'swim with' (you will swim with dolphins), 'encounter' (we encounter spectacular landscapes) and 'come within arm's length of' (come within arm's length of these beautiful creatures), helps to establish the relationship of an interconnection 
between mankind and nature. Yet, by granting humans the role of the Actor and natural phenomena the role of the Goal, the transitivity pattern maintains the human-nature power asymmetry, which could be challenged, were the roles to be reversed (e.g. wild animals will interact with you and dolphins will swim with you).

Finally, clauses containing processes of protection, including 'protect' (we help to protect the fragile desert environment), 'minimize' (minimize the use of water), 'reduce' (reduce our impact on the local environment) and 'avoid' (avoid pollution), promote tourists' active engagement in environmental conservation. Yet, while such clauses occur only in the last section of the advertisements (entitled 'Responsible tourism'), they are absent in the first two parts (labelled 'Description from the holiday company' and 'Day-by-day itinerary'). Thus, the explicit environmentalist discourse is spatially divided from, rather than incorporated into, tourism discourse in the data, disallowing the blending of the two. This corresponds to the findings reported in Stamou and Paraskevopoulos (2004), which reveal the separation of environmentalist and tourism images of a Greek ecotourist reserve in visitors books, resulting in the construction of dualism rather than a duality of ecotourism.

\section{Conclusion}

The analysis has revealed that the studied advertisements adopt a number of discursive devices that empower nature and resist the construction of humans as dominating it. These entail the adoption of the celebratory evaluative lexis evoking respect and humbleness towards nature, namely the construction of the image of nature as an aesthetically pleasing artwork and a spectacle of supernatural qualities, serving mainly as the object of a tourist's gaze, affection and admiration. Other evaluative meanings of nature with the empowering effect include prosperity, purity, fertility and healthiness. The advertisements also recurrently adopt a number of empowering transitivity configurations, such as the activation of tokens and the activation of experiences, and the allocation of the agentive role in constructive processes to inanimate natural elements, representing nature as a provider, a creator and the one that thrives.

Yet, the celebration and empowerment of nature in the ecotourism advertisements tend to take place at the expense of the reproduction of the human-nature dichotomy. The representations of nature as an aesthetically pleasing artwork and a spectacle of supernatural qualities construe nature as static and passive, and partially commodify nature by establishing it as a precious object resembling a gem. This finding corresponds to the conclusions of previous studies on ecotourism textual material (Dorsey et al. 2004, Stamou et al. 2009) revealing the portrayal of landscapes as unchangeable and outside 
the social realm. Commodification of the advertised natural elements is further subsumed in the allocated values of uniqueness and fame, foregrounding the aspect of 'difference'. The human-nature divide is also widened in the prevailing portrayal of natural phenomena that equates nature with wilderness, remote from civilization, pure and untouched by people. Nature thus tends to be portrayed as the Other, separated from mankind, hindering a holistic view of the two. When processes of interaction are used, rather than stating that humans and natural phenomena interact with each other, the role of the Actor is allocated solely to humans, with nature figuring as the affected of the interactional process. Furthermore, while the transitivity pattern in which humans have the role of the Actor and nature has the role of the Goal is repeatedly adopted in the data, the reversed transitivity pattern in which humans occupy the role of the Goal of the processes, the Actor of which is nature, is missing. On the whole, the discourse of the studied ecotourism advertisements seems to construct a boundary between mankind and nature, maintaining the dichotomy between the two.

\section{References}

Acott, T. G., La Trobe, H. L. and Howard, S. H. (1998) 'The evaluation of deep ecotourism and shallow ecotourism.' Journal of Sustainable Tourism, 6 (3), 238-253.

Boo, E. (1990) Ecotourism: The Potentials and Pitfalls. Washington: World Wildlife Fund.

Buckley, R. (2001) 'Tourism ecolabels.' Annals of Tourism Research, 29 (1), 183-208.

Buckley, R. (2003) Case Studies in Ecotourism. Oxon: Cabi Publishing.

Carrier, J. C. and Macleod, D. V. L. (2005) 'Bursting the bubble: The socio-cultural context of ecotourism.' Journal of Royal Anthropological Institute, 11, 315-334.

Ceballos-Lascuráin, H. (2003) 'Preface.' In: Lück, M. and Kirstges, T. (eds) Global Ecotourism Policies and Case Studies: Perspectives and Constraints Clevedon: Channel View Publications. viii-xiii.

Dorsey E. R., Steeves, H. L. and Porras, L. E. (2004) 'Advertising ecotourism on the internet: Commodifying environment and culture.' New Media and Society, 6 (6), 753-779.

Dowling, R. K. and Fennell, D. A. (2003) 'The context of ecotourism policy and planning.' In: Fennell, D. A. and Dowling, R. K. (eds) Ecotourism Policy and Planning. Oxon: Cabi Publishing. 1-20.

Fairclough, N. (1992) Discourse and Social Change. Cambridge: Polity Press.

Fennell, D. A. (2003) Ecotourism: An Introduction. $2^{\text {nd }}$ ed. London and New York: Routledge.

Fill, A. and Mühlhäusler, P. (2001) 'Introduction.' In: Fill, A. and Mühlhäusler, P. (eds) The Ecolinguistics Reader: Language, Ecology and Environment. London and New York: Continuum. 1-9.

Goatly, A. (2000) Critical Reading and Writing: An Introductory Coursebook. London and New York: Routledge.

Halliday, M. A. K. (1985) An Introduction to Functional Grammar. London: Edward Arnold. 
Halliday, M. A. K. (2001) 'New ways of meaning: The challenge to applied linguistics.' In: Fill, A. and Mühlhäusler, P. (eds) The Ecolinguistics Reader: Language, Ecology and Environment. London and New York: Continuum. 175-202.

Harré, R., Brockmeier, J. and Mühlhäuser, P. (1999) Greenspeak: A Study of Environmental Discourse. Thousand Oaks: Sage.

Hawkes, D. (2003) Ideology. $2^{\text {nd }}$ ed. London and New York: Routledge.

Krzyżanowski, M. and Forchtner, B. (2016) 'Theories and concepts in critical discourse studies: Facing challenges, moving beyond foundations.' Discourse and Society, 27 (3), 253-261.

Martin, J. R. and White, P. R. R. (2005) The Language of Evaluation: Appraisal in English. Basingstoke: Palgrave Macmillan.

Russell, A. (2007) 'Anthropology and ecotourism in European wetlands: Bubbles, babies and bathwater.' Tourist Studies, 7 (2), 225-244.

Stamou, A. G., Lefkaditou, A., Schizas, D. and Stamou, G. P. (2009) 'The discourse of environmental information: Representations of nature and forms of rhetoric in the information center of a Greek reserve.' Science Communication, 31 (2), 187-214.

Stamou, A. G. and Paraskevopoulos, S. (2004) 'Images of nature by tourism and environmentalist discourses in visitors books: A critical discourse analysis of ecotourism.' Discourse and Society, 15 (1), 105-129.

The Ecologist. Online document: http://www.theecologist.org/, retrieved on 25 August 2015.

Thurlow, C. and Jaworski, A. (2010) Tourism Discourse: Language and Global Mobility. Basingstoke: Palgrave Macmillan.

Urry, J. (2002) The Tourist Gaze: Leisure and Travel in Contemporary Societies. $2^{\text {nd }}$ ed. London: Sage.

Weiss, G. and Wodak, R. (eds) (2003) Critical Discourse Analysis: Theory and Interdisciplinarity. Basingstoke: Palgrave Macmillan.

Wodak, R. and Meyer, M. (eds) (2009) Methods of Critical Discourse Analysis. $2^{\text {nd }}$ ed. London: Sage.

Wodak, R. (2009) 'What CDA is about: A summary of its history, important concepts and its developments.' In: Wodak, R. and Meyer, M. (eds) Methods of Critical Discourse Analysis. $2^{\text {nd }}$ ed. London: Sage. 1-13.

\section{Sources:}

Responsible Travel. Online document: http:/www.responsibletravel.com/, retrieved on 25 August 2015.

Dita Trčková is Assistant Professor of English Linguistics at Tomas Bata University in Zlín, Czech Republic. Her research interests include topics from the field of critical discourse analysis, namely the investigation of power asymmetries and reproduction of and resistance to stereotypes in newspaper discourse. Her latest publications are concerned with representations of the human-nature relationship in media.

Address: Mgr. Dita Trčková, Ph.D., Department of Modern Languages and Literatures, Faculty of Humanities, Tomáš Bat’a University, nám. T. G. Masaryka 1279, Zlín, 760 01, Zlín, Czech Republic. [e-mail: trckova@fhs.utb.cz] 